\section{Interaction of Spinel Crystals and Chromium Nitride in Chromium}

IT has been amply demonstrated that normally brittle metals exhibit substantial ductility at low temperatures when interstitial impurity-levels are extremely low. This is particularly true for interstitial nitrogen in chromium ${ }^{1}$. As little as 15 p.p.m. nitrogen has been reported to embrittle chromium ${ }^{2}$.

A rather unexpected result occurs when a spinelforming oxide such as magnesium oxide is added to chromium. The composite mixture exhibits ductility at room temperature after hot-working for densification ${ }^{3}$.

$\mathrm{X}$-ray experiments confirm that magnesium-chromite spinel forms as magnesium oxide combines with oxygen and chromium in the powder mixture. We believe that the spinel formed in this manner enhances ductility by absorbing nitrogen contained in the chromium.

A composite containing $\mathbf{9 3 . 5}$ per cent electrolytic chromium, 0.5 per cent titanium, and 6 per cent mag. nesium oxide has been examined in an experiment involving exposure to nitrogen in order to investigate the effect produced by the spinel. The composite mixture was first fabricated by mixing powders of chromium, titanium and magnesium oxide, compacting hydrostatically, sintering, and then extruding.

The extruded composite mixture contains larger amounts of interstitials (120 p.p.m. nitrogen, for example) than the maximum allowable limits normally quoted for ductility. Nevertheless, this material demonstrates ductility in tension and in bending at room temperature. The physical properties of the material, including notch tensile results, have been previously reported ${ }^{4}$.

Sintered and wrought chromium composite material containing magnesium -chromite spinel, as explained here, was exposed at $1,200^{\circ} \mathrm{C}$ in argon containing 100 p.p.m. nitrogen, quenched in water, and examined metallographically. The first electron micrograph (Fig. 1) shows the structure. Fine nitride needles are present in the matrix. The sample was then aged $1 \mathrm{~h}$ at $100^{\circ} \mathrm{C}$, resulting in growth of the nitride particles, as seen in Fig. 2. The material was completely embrittled at this stage. It was then held for $4 \mathrm{~h}$ at $1,425^{\circ} \mathrm{C}$ in moderate vacuum. The resulting structure is shown in Fig. 3. The photomicrograph demonstrates that the nitride has completely disappeared from the matrix.

It would seem likely that the spinel crystals absorbed the precipitated nitride. The photomicrograph offers evidence to this effect. A very fine amorphous material has collected around the ceramic grains. This material was removed in the process of replicating the polished. and etched specimen for the electron microscope. No

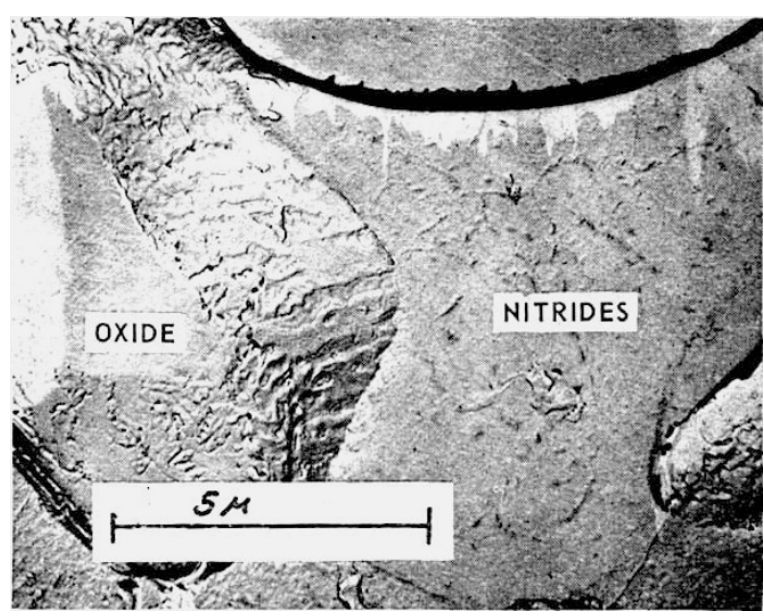
Fig. 1. Chromium nitride needles after quenching (electron micrograph

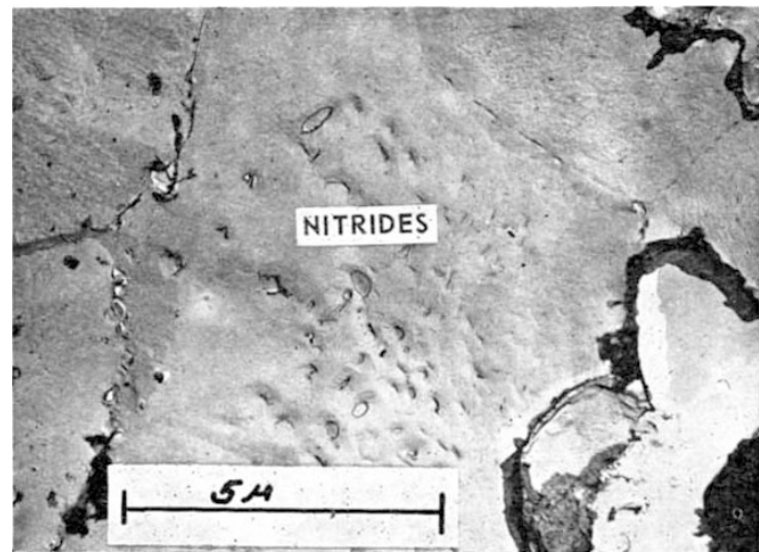

Fig. 2. Chromium nitrides after $100^{\circ} \mathrm{C}$ ageing (electron micrograph replica)

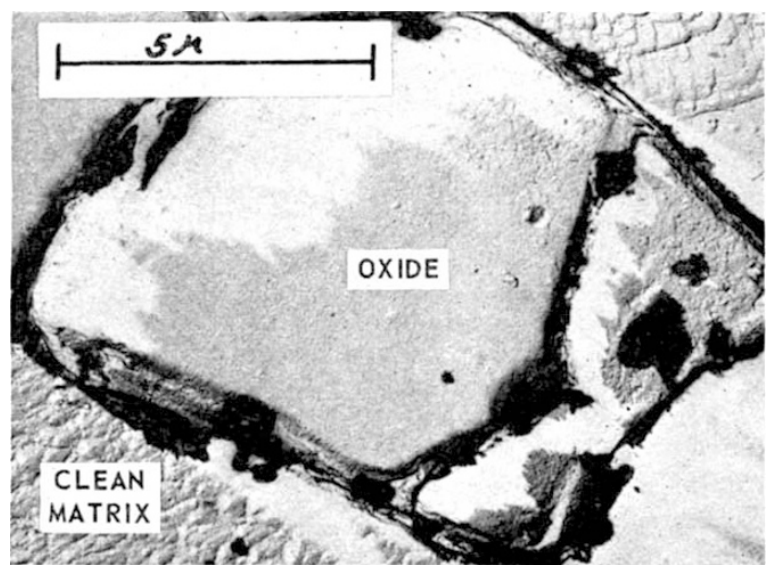

Fig. 3. Reaction product at oxide particle after $1,425^{\circ} \mathrm{C}$ solution treatment (electron micrograph with extraction technique)

electron diffraction pattern could be obtained from it, indicating that it was amorphous or composed of very small crystals. The composite was ductile and could be bent at room temperature after this heat treatment.

It is possible that the chromium nitride would break down at $1,425^{\circ} \mathrm{C}$ and go into solution, the nitrogen recombining at the metal surface or simply subliming. Accordingly, a sample of pure electrolytic chromium, containing no magnesium oxide, was fabricated, extruded, and exposed to nitrogen in the same manner. Nitrides were still present in quantity after the $1,425^{\circ} \mathrm{C}$ heat treatment, including heavily nitrided grain boundaries.

In conclusion, then, it can be said that a dispersed spinel phase exhibits the important property of chemically rendering the matrix free from nitride precipitates. This effect further lowers the amount of nitrogen contained in the matrix to values low enough to promote room temperature ductility.

I thank Mr. Conrad Herald for the electron micrographs.

David M. Scrugas

Research Laboratories,

The Bendix Corporation,

Southfield, Michigan.

${ }^{1}$ Allen, B. C., May Kuth, D. J., and Jaffee, R. I., Influence of Impurity Elements, Structure, and Prestrain on Tensile Transition of Chromium,

${ }^{2}$ Weaver, C. W., Nature, 180,806 (1957).

${ }^{3}$ Scruggs, D. M., ARS Journal, 31, 11 (1961).

"Reed, G. C., and Schalliol, W., J. Metals, N.Y., 16 (1964). 